\title{
Clinical implications of somatostatin-receptor scintigraphy in ophthalmic Graves' disease
}

\author{
Annamaria Colao, Rosario Pivonello, Secondo Lastoria ${ }^{1}$, Antongiulio Faggiano, Diego Ferone, Gaetano Lombardi \\ and Gianfranco Fenzi \\ Departments of Molecular and Clinical Endocrinology and Oncology, 'Federico II' University of Naples, Via Sergio Pansini, 5, 80131, Naples, Italy, and \\ ${ }^{1}$ Nuclear Medicine, National Cancer Institute of Naples, Italy \\ (Correspondence should be addressed to A Colao,Email: colao@unina.it)
}

\section{Introduction}

The eye complications associated most typically with hyperthyroidism caused by Graves' disease range from discomfort and lid retraction to disfiguring proptosis, diplopia and sight loss $(1,2)$. Usually called Graves' ophthalmopathy, this condition is better termed thyroid-associated ophthalmopathy (TAO), emphasising the wide spectrum of thyroid disorders in these patients. TAO is one of the most difficult autoimmune disorders to investigate; it is characterised by enlargement of the extraocular muscles and an increase in the retrobulbar fat, which cause eye proptosis, the main clinical manifestation of the disease (Table 1). Involvement of the cornea, the optic nerve and orbital soft tissues may occur during the natural course of the disease (3).

An exact in vivo characterisation of the underlying patho-physiological mechanism of TAO has remained difficult because the affected retrobulbar space is not easily accessible. The identification of patients with Graves' ophthalmopathy is based primarily on clinical signs and symptoms affecting one or both eyes (4). Additional information can be obtained from conventional imaging methods such as magnetic resonance imaging (MRI) or computed tomography (CT), which allow gross changes in the retrobulbar space (e.g. muscle swelling, oedema or fibrosis) to be recognised $(1,2)$. By using histology, orbital infiltration with activated T lymphocytes and evidence of local release of cytokines and interactions of lymphocytes with retrobulbar fibroblasts have been demonstrated, suggesting that TAO is an organ-specific autoimmune disease (1, $2,5,6)$. Although it is accepted that the pathogenesis of TAO is almost certainly multifactorial, the trigger event seems to be the activation of $\mathrm{T}$ cells directed against a thyroid follicular cell antigen(s) that then recognise and bind to a similar antigen(s) in orbital tissue $(1,2,6)$. Thereafter, these activated orbital T cells release a variety of substances and stimulate excessive production of glycosaminoglycans and collagen by orbital fibroblasts. This causes the inflammatory and oedematous changes of thyroid ophthalmopathy (7). In fact, during the early stages of the disease, macrophages, highly specialised $\mathrm{T}$ cells, mast cells and, occasionally, plasma cells infiltrate the orbital connective, adipose and muscle tissue. Several cytokines, such as interferon- $\gamma$, tumour necrosis factor- $\alpha$, interleukin1 and transforming growth factor- $\beta$, as well as growth factors, such as insulin-like growth factor-I (IGF-I) and platelet-derived growth factor, have been detected within the orbital tissues (5-8). All these substances are probably produced both by infiltrating immunocompetent cells and by residential fibroblasts, adipocytes, myocytes and microvascular endothelial cells (9). Cytokines and growth factors stimulate cell proliferation, glycosaminoglycan synthesis and expression of immunomodulatory molecules in orbital fibroblasts and microvascular endothelial cells (Table 2).

No consensus exists regarding the common antigen in the orbit and thyroid, the thyrotrophin (thyroid-stimulating hormone, TSH) receptor or a variant, or on the role of circulating antibodies against extraocular muscle and fibroblast components. The finding of expression of the TSH receptor in retro-orbital tissue may provide the link, previously lacking, between orbital involvement and thyroid disease in Graves' disease. Thyroid-stimulating antibodies directed against the TSH receptor could interact with the orbital components that express the receptor, thus stimulating glycosaminoglycans, cellular matrix proteins and connective tissue production and bringing about antibodydependent cell-mediated cytotoxicity mediated by natural killer cells. On the other hand, T cells that react with the TSH receptor will be targeted to the orbit where, in the presence of the antigen, they will secrete various cytokines that stimulate fibroblasts to proliferate, to express the major complex of histocompatibility class II antigens and to synthesize collagen and connective tissue (10).

\section{The natural course of TAO}

TAO goes through different stages. In the early stage of the disease, the retrobulbar tissue shows marked lymphocytic infiltration and interstitial oedema, whereas in the later stages fatty infiltration and fibrosis are observed $(1,2)$. A clinical ocular examination is not always able to identify the stage of the pathologic process or, in particular, the presence or absence of fibrosis $(1,2)$. Thus, it is often hard to distinguish clinically active inflammatory early-stage disease from 
Table 1 Main clinical characteristics of thyroid-associated ophthalmopathy and their hypothesised mechanisms (modified from Wall et al. (5)).

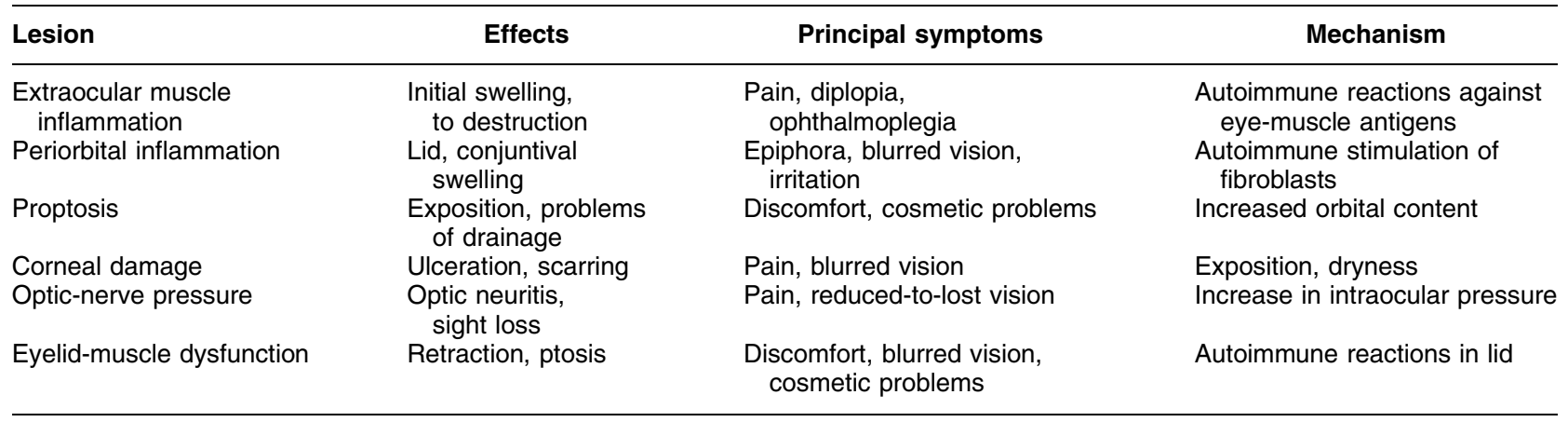

stable, fibrotic, end-stage disease. The clinical definition of the activity of the ophthalmopathy at the initial presentation is crucial to the identification of the correct therapeutic approach. The treatment of TAO is based on immunosuppressive therapy, such as the use of corticosteroids or radiation, or surgical therapy $(1,2)$. Immunosuppression is considered beneficial only in the early active stage, whereas surgery represents the treatment for the end stage of the disease. On the basis of this evidence, a new approach, using labelled somatostatin analogues intended to highlight the presence of activated $\mathrm{T}$ lymphocytes in orbital tissue, was attempted in order to identify the early stage of TAO, which should be particularly sensitive to immunosuppressive treatment.

\section{Somatostatin-receptor scintigraphy (SRS) in the pretreatment evaluation of TAO}

The definition of the clinical phase of TAO in the individual patient is relevant to the selection of the most appropriate treatment, since immunosuppressive therapy would be successful in the early active phase, but surgery (such as orbital decompression and eyemuscle and eyelid correction) is indicated for the end phase of the disease $(1,2)$. Clinical scores, laboratory methods (such as assay of urinary glycosaminoglycan excretion) and imaging techniques (such as MRI) are used to this end, though they show poor sensitivity.

Recently, the availability of radionuclide-coupled somatostatin analogue has enabled the in vivo detection of malignancies (which express somatostatin receptors) by using standard $\gamma$-cameras. Somatostatin receptors have been ubiquitously identified, mostly on cells of neuroendocrine origin, but also on cells (e.g. lymphocytes) not originating from neuroendocrine precursors (11). In fact, SRS is used to detect disease sites in neuroendocrine and non-neuroendocrine malignancies (12) and to reveal the presence of activated lymphocytes in inflammatory foci of several autoimmune diseases such as rheumatoid arthritis and Sjögren's disease (13). SRS has been proposed to select candidates responsive to specific peptide treatment (14-16), though in patients with pituitary adenomas this latter evidence is under debate $(17,18)$. A potentially relevant role for SRS in the pretreatment evaluation of TAO has been suggested recently (19). In fact, orbital tissues significantly accumulate ${ }^{111}$ In-DTPA-D-Phe ${ }^{1}$ octreotide in patients with TAO $(4,20-26)$. Postema et al. (20) reported a positive correlation between clinical activity score and radiotracer uptake in 32 patients with TAO: they used a semi-quantitative scoring system measuring the skull:orbit ratio on SPECT reconstruction $5 \mathrm{~h}$ after the injection of $220 \mathrm{MBq}{ }^{111}$ In-DTPA-D-Phe ${ }^{1}$-octreotide. Kahaly et al.

Table 2 Effects of different cytokines and growth factors and their main sources in the peripheral circulation (modified from Weetman (6)).

\begin{tabular}{lll}
\hline Cytokine/Growth factor & \multicolumn{1}{c}{ Source } & Effect on fibroblasts \\
\hline Interleukin-1 & Macrophages & Stimulates proliferation \\
Tumour necrosis factor- $\alpha$ & Macrophages & Stimulates proliferation (variable) and collagen synthesis \\
Fibroblast growth factor & Macrophages & Stimulates proliferation \\
Platelet-derived growth factor & Macrophages, platelets & Stimulates proliferation and collagen synthesis \\
Transforming growth factor- $\beta$ & Macrophages, T cells & Stimulates fibrosis \\
Interferon- $\beta$ & Macrophages, T cells & Inhibits proliferation \\
Lymphotoxin & T cells & Stimulates proliferation \\
Interferon- $\gamma$ & T cells & Inhibits proliferation and collagen synthesis \\
Fibroblast-activating factors & T cells & Stimulates proliferation of connective tissue
\end{tabular}


1

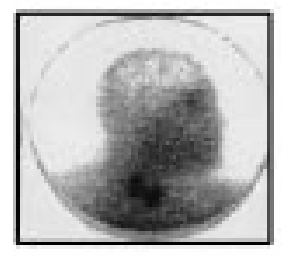

2

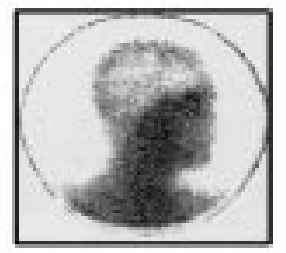

3

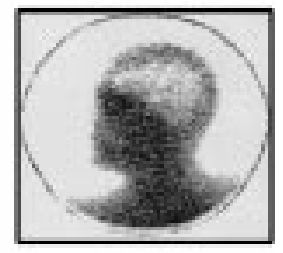

Figure 1 Results of orbital ${ }^{111}$ In-DTPA-DPhe ${ }^{1}$-octreotide SRS in three representative patients with clinically active Graves' ophthalmopathy, before and after treatment. Clinical details are shown in the table below; RE, right eye; $\mathrm{LE}$, left eye. Data are modified from Colao et al. (28).

\begin{tabular}{|c|c|c|c|c|c|c|c|}
\hline \multirow{3}{*}{$\begin{array}{c}\text { Patient } \\
\text { (genderíage) }\end{array}$} & \multirow{3}{*}{$\begin{array}{l}\text { Disease } \\
\text { duration } \\
\text { Gyeurs| }\end{array}$} & & & \multicolumn{4}{|c|}{ Ophthaimopathy index } \\
\hline & & \multicolumn{2}{|c|}{ SRS soore } & \multicolumn{2}{|c|}{ RE } & \multicolumn{2}{|c|}{ LE } \\
\hline & & RE & LE & before & stter & before & after \\
\hline 1. M/47 & 4 yrs & 0 & 0 & 21 & 21 & 14 & 13 \\
\hline 2. M/30 & $1 \mathrm{yr}$ & 2 & 1 & 18 & 11 & 18 & 13 \\
\hline 3. M/28 & $0.5 \mathrm{yr}$ & 2 & 2 & 19 & 11 & 15 & 10 \\
\hline
\end{tabular}

(21) reported that the uptake of ${ }^{111}$ In-DTPA-D-Phe ${ }^{1}$ octreotide (measured quantitatively as counts/voxel orbit:brain ratio on filtered, transverse/oblique orbital SPECT reconstruction 4 and $24 \mathrm{~h}$ after the injection of $110 \mathrm{MBq}$ radiotracer) was significantly higher in 34 patients with clinically active TAO than in 6 patients with inactive disease and in 10 controls. Similarly, Gerding et al. (26) reported that visual semi-quantitative analysis of $4 \mathrm{~h} / 24 \mathrm{~h}$ planar images during SRS was correlated with the ophthalmologic progression. Conversely, no significant correlation between the ${ }^{111} \mathrm{In}$ DTPA-D-Phe ${ }^{1}$-octreotide activity and the degree of ophthalmopathy (determined using Werner's classification) was reported by Durak et al. (24). Taken together, these studies suggested that orbital uptake of labelled octreotide can be used to determine the pathological phase of TAO. A high degree of accumulation (positive) occurs in the active early phase, whereas no uptake/ faint uptake occurs during the stable (end phase) of the disease. This finding was thought to be due to the presence or absence of activated lymphocytes respectively in the early and end phase of the disease. Specific binding of ${ }^{111}$ In-DTPA-D-Phe ${ }^{1}$-octreotide to somatostatin receptors on eye myocytes, fibroblasts or endothelial cells, however, cannot be ruled out (27).

As the presence of activated lymphocytes in the orbit represents the first requisite for the effectiveness of corticosteroid therapy and as it can be revealed by SRS, we recently attempted this approach in patients with TAO. The results of orbital ${ }^{11}$ In-DTPA-D-Phe ${ }^{1}$-octreotide uptake predicted the response to corticosteroid therapy in these patients (28). In 10 patients with TAO undergoing SRS before corticosteroid therapy (methylprednisolone, $1 \mathrm{~g}$ i.v. on 2 consecutive days each week for 6 weeks), clinical activity was evaluated before and after treatment by calculating the ophthalmopathy index (OI), in accordance with Bartalena et al. (29). Planar and SPECT images of the head were obtained $24 \mathrm{~h}$ after the i.v injection of $120-190 \mathrm{MBq}{ }^{111} \mathrm{In}$ DTPA-D-Phe ${ }^{1}$-octreotide. The radioligand uptake within each orbit and the brain was calculated by using the 'regions-of-interest' method with planar images. Using the orbit:brain ratio, the images were analysed using a three-point semi-quantitative score: 0 , negative uptake;

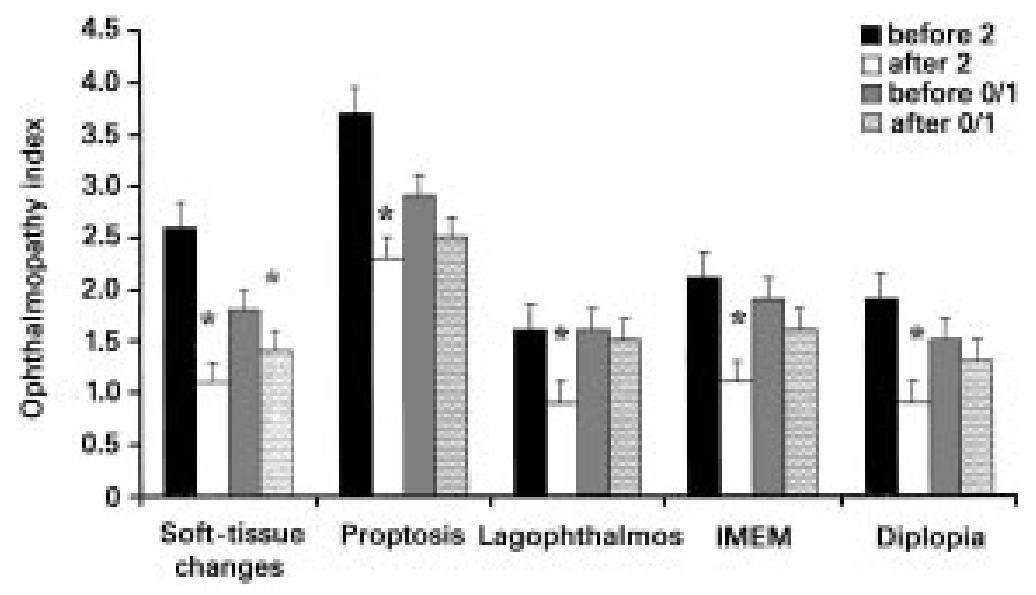

Figure 2 Results of treatment with methylprednisolone $(1 \mathrm{~g}$, i.v.) on different ocular signs in 10 patients with clinically active Graves' ophthalmopathy, grouped on the basis of ${ }^{111}$ In-DTPA-D-Phe ${ }^{1}$ octreotide scintigraphy results. Scores: 0 , negative uptake (orbit:brain ratio $<1$ ); 1 , faint uptake (orbit:brain ratio $>1$ to $<2.5$ ); 2, well-defined uptake (orbit:brain ratio $>2.5)$. ${ }^{*} P<0.05$ vs basal values. Data are modified from Colao et al. (28). See the figure for the key to the SRS scores before and after treatment. IMEM, impairment of muscle eye movements. 
A

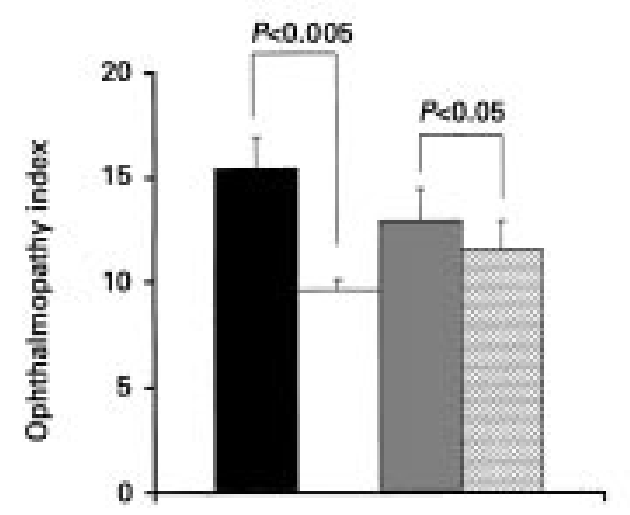

B

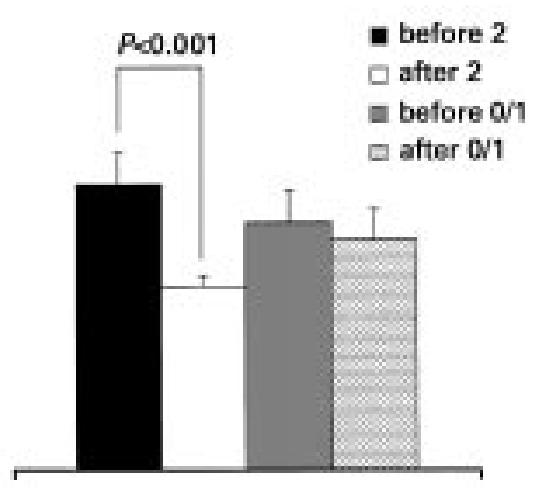

Figure 3 Results of treatment with methylprednisolone (1 g, i.v.) on ocular signs, including (A) or not including (B) soft-tissue swelling, in 10 patients with clinically active Graves' ophthalmopathy, grouped on the basis of ${ }^{111}$ In-DTPA-D-Phe ${ }^{1}$-octreotide scintigraphy results. Scores: 0 , negative uptake (orbit:brain ratio $<1$ ); 1 , faint uptake (orbit:brain ratio $>1$ to $<2.5$ ); 2 , well-defined uptake (orbit:brain ratio >2.5). Patients were grouped as in Fig. 2. Data are modified from Colao et al. (28).

1, faint uptake $(0-2.5) ; 2$, well-defined uptake $(>2.5)$ (Fig. 1). After treatment, a significant change in the OI was observed both in orbits with scores of 2 and in those with scores of 1 or 0 in SRS (Fig. 2). However, when the OI was calculated excluding the soft-tissue changes, which occur after corticosteroid treatment independently of the phase of disease activity, a significant change was observed in the orbits with scores of 2 but not in those with scores of 0 or 1 (Fig. 3 ). In particular, 6 weeks after corticosteroid treatment, 7 patients with orbital scores of 2 in the scintigraphy had significant improvements in soft-tissue inflammation, proptosis, lagophthalmos, extraocular muscle-movement impairment and diplopia after treatment, whereas patients with scores of 0 or 1 had significant changes only in symptoms with soft-tissue involvement (28). Lending further support to our previous observation, Nocaudie et al. (30), in a prospective study on 17 patients presenting with severe ophthalmopathy, used hormonal and immunological investigations, orbital radiological imaging (CT scans or MRI), visual functional examinations and orbital SRS before the start of steroid and/or radiotherapy treatment. Orbital images were analysed $4 \mathrm{~h}$ and $24 \mathrm{~h}$ after the i.v. injection of $111 \mathrm{MBq}{ }^{111}$ In-DTPA-D-Phe ${ }^{1}$-octreotide on planar imaging centred on the head and neck (the anterior view and both lateral views), and retrobulbar uptake was assessed by visual semi-quantitative and quantitative analyses. After 6 months of treatment, they found that all 10 patients with positive SRS results showed clinical improvement at 6 months, whereas 6 of the 7 patients with negative SRS results had not improved. Although a larger group of patients should be investigated before definitive conclusions can be drawn, SRS seems to be a useful method for predicting the clinical response to immunosuppressive treatment in patients with TAO. This might avoid the use of corticosteroid therapy in patients for whom it would have only adverse effects, and might delay surgical treatment for those patients who could benefit from other kinds of medical therapy.

Furthermore, Kahaly et al. (25), in a longitudinal prospective study carried out in 20 patients with active TAO, demonstrated that ${ }^{111}$ In-DTPA-D-Phe ${ }^{1}$-octreotide uptake in both orbits was significantly lower after corticosteroid and irradiation treatment than at the baseline. The orbit:brain ratio of ${ }^{111}$ In-DTPA-D-Phe ${ }^{1}$ octreotide decreased significantly both after $4 \mathrm{~h}$ (from 25 to 6.2 ) and after $24 \mathrm{~h}$ post-injection (from 9.6 to 2.7) (25). The decrease in radiotracer uptake was paralleled by a significant reduction in proptosis (from 25 to $23 \mathrm{~mm}, P<0.01$ ), in medical rectus-muscle diameter (from 9 to $7 \mathrm{~mm}, P<0.01$ ) and in inferior rectus-muscle diameter (from 10 to $7 \mathrm{~mm}, P<0.01$ ), which induced a remarkable improvement in visual acuity (25). Similar data were reported by Moncayo et al. (4), who described a significant decrease in ${ }^{111} \mathrm{In}$ DTPA-D-Phe ${ }^{1}$-octreotide uptake after immunosuppressive therapy in 20 patients with high activity scores, pointing out that in patients with persistent eye disease SRS results remained positive. On this basis, changes in orbital ${ }^{111}$ In-DTPA-D-Phe ${ }^{1}$-octreotide uptake after immunosuppressive therapy indicated that SRS can be useful for monitoring the effects of treatment.

\section{Somatostatin analogues in the treatment of TAO}

Treatment with somatostatin analogues to cure patients with active Graves' ophthalmopathy is based upon the evidence that significant uptake of labelled octreotide occurs. In an uncontrolled study, octreotide 
Table 3 Overview of the effect of somatostatin-analogue treatment in thyroid-associated ophthalmopathy

\begin{tabular}{|c|c|c|c|c|c|c|}
\hline Author & Ref. no & No. of patients & Drug & Dose & Duration & Improvement \\
\hline Chang (1992) & 31 & 6 & Octreotide & $300 \mu \mathrm{g} /$ day & 3 months & 6 \\
\hline Krassas (1995) & 33 & 12 (8 controls) & Octreotide & $300 \mu \mathrm{g} /$ day & 3 months & 7 \\
\hline Ozata (1996) & 34 & 10 & Octreotide & $300 \mu \mathrm{g} /$ day & 3 months & 8 \\
\hline Kung (1996) & 35 & 8 (10 controls $\left.{ }^{\star}\right)$ & Octreotide & $600 \mu \mathrm{g} /$ day & 3 months & $8(10)$ \\
\hline Uysal (1999) & 36 & 9 & Octreotide & $300 \mu \mathrm{g} /$ day & 3 months & 7 \\
\hline Krassas (1999) & 40 & 5 (5 controls) & Lanreotide & $80 \mathrm{mg} / \mathrm{month}$ & 3 months & 5 \\
\hline
\end{tabular}

*The control group was treated with methylprednisolone; ${ }^{\star *}$ one control patient deteriorated during the follow-up.

was shown to have a beneficial effect on 6 patients with active TAO and pretibial mixedema (31). Although the results for the latter symptom were controversial (32), for TAO several studies reported variable degrees of effectiveness of somatostatin analogues.

In a controlled study, Krassas et al. (33) evaluated low-dose octreotide treatment $(0.3 \mathrm{mg} /$ day $)$ in 12 patients with moderately severe Graves' ophthalmopathy. They found a positive correlation between the orbital score with SRS and the result of treatment. After octreotide treatment, 6 patients experienced improvement in ocular manifestations, as assessed by clinical criteria and changes in the NOSPECS score in both eyes (and for one patient in one eye); the remaining 5 patients showed no improvement. The patients showing clinical improvement had positive orbital scans, whereas (with one exception) the patients who did not improve had negative orbital scans (33).

Beneficial effects of octreotide treatment were also found in 8 out of 10 patients with moderately severe active TAO; octreotide treatment was reported as being particularly successful in patients with soft-tissue involvement (class II or III) (34). In comparison with corticosteroid treatment, octreotide treatment was similarly able to reduce palpebral opening and the activity score after 3 months, but overall the activity score was lower after corticosteroid treatment than after octreotide treatment (35). However, only corticosteroid treatment, and not octreotide, was able to reduce the intraocular pressure and muscle size, as documented by MRI (35). By contrast, neither octreotide nor corticosteroids significantly improved proptosis, whereas glycosaminoglycan excretion was reduced after both treatments (35). No beneficial effects of octreotide treatment were reported by Durak et al. (24) in 3 patients with active TAO, despite the use of a high dose of the drug ( $1 \mathrm{mg} /$ day). Uysal et al. (36) recently reported the effects of a 3-month treatment with octreotide at a dose of $300 \mu \mathrm{g} /$ day in 9 patients with TAO and positive clinical activity scores and who were either unresponsive to, or unsuitable for, glucocorticoid treatment. Proptosis, measured with the Hertel exophthalmometer, slightly improved after the treatment either for the right eye $(22.0 \pm 3.0 \mathrm{vs} 19.6 \pm 2.4)$ or for the left eye $(22.2 \pm 1.9$ vs $20.2 \pm 2.2)$, and the whole activity score fell significantly (36). As a whole, 7 out of 9 patients responded favourably to octreotide treatment, whereas the remaining 2 patients did not respond; the improvement lasted for 20 months of follow-up in 4 out of the 7 responders (36). The beneficial effect of octreotide in these patients allowed the authors to suggest that this treatment can be used in patients who are unresponsive to glucocorticoid treatment or who cannot use these drugs for some reason.

Recently, lanreotide (another somatostatin analogue, provided in a slow-release formulation) has become available for clinical use for acromegaly as well as for other somatostatin-receptor-positive tumours. Lanreotide was shown to be as effective as octreotide in suppressing growth hormone and IGF-I in acromegaly but is better tolerated, mainly because of the easy administration one to three times per month (37-39). Lanreotide was administered at a dose of $40 \mathrm{mg}$ every 2 weeks, over a period of 3 months, to 5 patients with severely active TAO positive orbital scans after ${ }^{111}$ InDTPA-D-Phe ${ }^{1}$-octreotide treatment (40). Four of the 5 patients showed a significant improvement in symptom scores in both eyes, and the remaining patient showed improvement in one eye (40). Orbital scintigraphy was repeated at the end of the third month of treatment and was negative for all patients. These data were confirmed in a very recent study from the same group (41). An overview of the effects of somatostatin-analogue treatment of TAO is shown in Table 3.

\section{Mechanisms of action of somatostatin analogues in TAO}

The potential clinical applications, as well as the exact mechanism of action of somatostatin analogues in active TAO, remain to be fully elucidated. It has been suggested that somatostatin analogues suppress peripheral IGF-I activity and that the inhibition of IGF-Imediated action may be a promising strategy for controlling the inflammatory process and its deleterious consequences (42). Recent data showed that orbital lymphocytes and fibroblasts from patients with active TAO express IGF-I receptors and produce IGF-I, which stimulates glycosaminoglycan production and collagen secretion $(7,43)$. In addition, it was also hypothesised that IGF-I stimulates orbital fibroblasts to up-regulate the expression of the hyaluronate receptor CD44, which mediates orbital lymphocyte homing and 
A

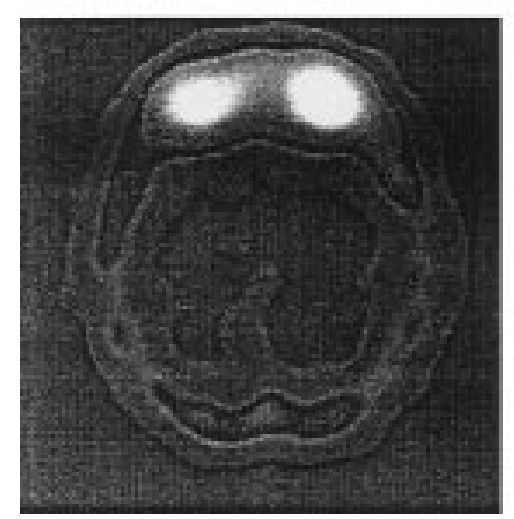

B

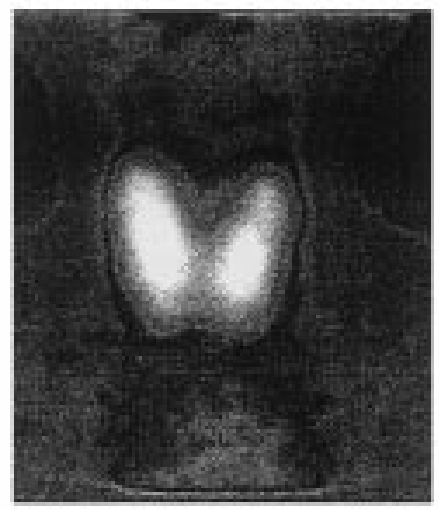

C

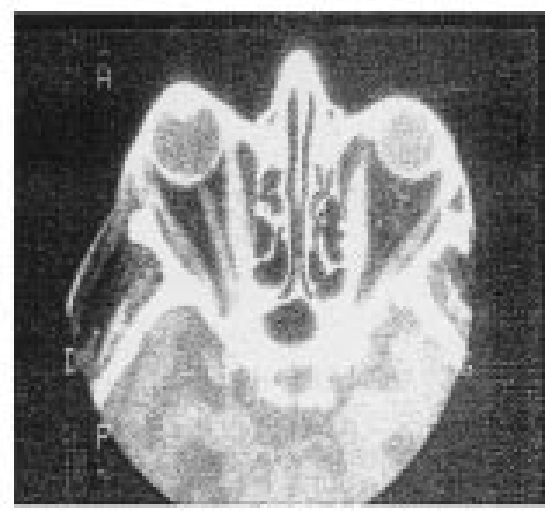

Figure 4 Results of orbital (A) and thyroid (B) ${ }^{111}$ In-DTPA-D-Phe ${ }^{1}$-octreotide scintigraphy as compared with an orbital CT scan (C) in one patient with clinically active Graves' ophthalmopathy.

retention and produces a tissue inhibitor of metalloproteinase (TIMP-1), a potent inhibitor of orbital matrix remodelling $(43,44)$. Moreover, IGF-I derived from fibroblasts may inhibit apoptosis in orbital lymphocytes, thereby extending their survival and perpetuating the inflammatory process. On the other hand, mitogen-activated lymphocytes express IGF-II receptors in addition to IGF-I and secrete at least four different IGF-binding proteins. The evidence that human lymphocytes express IGF-I, IGF-II and IGFbinding proteins suggests that the IGF-I system plays a relevant role in human lymphocyte function. Another possible mechanism could be direct inhibition of the release of lymphokines from T-lymphocytes (45). Cytokines produced by orbital macrophages or by infiltrating activated lymphocytes (Table 2) are considered to be involved both in triggering and in perpetuating the sequence of reactions occurring in the retro-orbital space in ophthalmopathy and, eventually, leading to clinical disease through stimulation of glycosaminoglycan synthesis by orbital fibroblasts (1, 2 ). In addition, some of these cytokines stimulate the expression, by orbital fibroblasts, of immunomodulatory proteins such as human leukocyte antigen DR, heat-shock protein 72 and intercellular adhesion molecules, thus perpetuating the autoimmune response in orbital connective tissues $(19,43)$.

Finally, the effect of somatostatin analogues could be mediated by specific receptors expressed by $\mathrm{T}$ and $\mathrm{B}$ lymphocytes (11). Somatostatin receptors have been identified within the orbital tissues of TAO both in vivo and in vitro (19).

\section{Conclusions}

The role of the scintigraphy using ${ }^{111}$ In-DTPA-D-Phe ${ }^{1}$ octreotide as well as of treatment with somatostatin analogues in TAO is still under debate. Patients with very active eye disease are likely to respond favourably to immunosuppression: in these patients, the activity of ophthalmopathy is clinically evident and further assessment with ${ }^{111}$ In-DTPA-D-Phe ${ }^{1}$-octreotide scintigraphy could be considered unnecessary. In many patients with moderately severe ophthalmopathy, however, it is not clear whether or not eye disease is still in the active stage and, thus, whether or not the patient will benefit from immunosuppression. In these cases, orbital scintigraphy using ${ }^{111}$ In-DTPA-D-Phe ${ }^{1}$-octreotide might be used as a predictor for the outcome of immunosuppressive treatments. However, prediction using the technique of orbital SRS requires great accuracy, so each institution should develop its own cut-off values (45). Scintigraphy is an expensive method with a not-inconsiderable radiation burden. The future availability of somatostatin analogues labelled with ${ }^{99 m_{\text {technetium could overcome }}}$ such problems. Moreover, orbital scintigraphy with ${ }^{111}$ In-DTPA-D-Phe ${ }^{1}$-octreotide is not specific, since positive scans may be obtained in patients with orbital meningioma, malignant lymphoma, pseudo-tumour orbitae, orbital myositis, sarcoidosis, Wegener's granulomatosis, necrotizing scleritis, sinusitis or infections of the nasal mucosa $(24,45)$. Finally, orbital scintigraphy does not allow precise imaging and thus the evaluation of eye-muscle swelling and apical crowding still requires imaging with CT or MRI scans (Fig. 4). Similarly, treatment of Graves' ophthalmopathy with somatostatin analogues needs further validation from controlled studies before it can be considered as an alternative to the standard immunosuppressive treatment with steroids and irradiation.

\section{References}

1 Burch HB \& Wartofsky L. Graves' ophthalmopathy: current concepts regarding pathogenesis and management. Endocrine Review $199314747-793$. 
2 Jacobson DH \& Gorman CA. Endocrine ophthalmopathy: current ideas concerning etiology, pathogenesis and treatment. Endocrine Review 19845 200-220.

3 Bahn RS \& Heufelder AE. Pathogenesis of Graves' ophthalmopathy. New England Journal of Medicine $1993 \mathbf{3 2 9} 1468$ 1475.

4 Moncayo R, Baldissera I, Decristoforo C, Kendler D \& Donnemiller E. Evaluation of immunological mechanisms mediating thyroid-associated ophthalmopathy by radionuclide imaging using the somatostatin analog ${ }^{111}$ In-octreotide. Thyroid 1997 7 21-29.

5 Wall JR, Salvi M \& Bernard NF. Thyroid associated ophthalmopathy: a model for the association of organ-specific autoimmune disorders. Immunology Today 199112 150-153.

6 Weetman AP. Thyroid-associated eye disease: pathophysiology. Lancet 1991338 25-28.

7 Smith TJ, Bahn RS, Gorman CA \& Cheavens M. Stimulation of glycosaminoglycan accumulation by interferon gamma in cultured retro-ocular fibroblasts. Journal of Clinical Endocrinology and Metabolism 199172 1169-1171.

8 Heufelder AE. Pathogenesis of Graves' ophthalmopathy: recent controversies and progress. European Journal of Endocrinology $1995132532-541$.

9 Heufelder AE \& Scriba P. Characterization of adhesion receptors on cultured microvascular endothelial cells derived from the retroorbital connective tissue of patients with Graves' ophthalmopathy. European Journal of Endocrinology 1996134 51-60.

10 Feliciello A, Porcellini A, Ciullo I, Bonavolontà G, Avvedimento EV \& Fenzi G. Expression of thyrotropin-receptor mRNA in healthy and Graves' disease retro-orbital tissue. Lancet 1993342 337-338.

11 Hofland LJ, van Hagen PM \& Lamberts SW. Functional role of somatostatin receptors in neuroendocrine and immune cells. Annals of Medicine 19992 23-27.

12 Lamberts SWJ, Bakker WH, Reubi JC \& Krenning EP. Somatostatin receptor imaging. New England Journal of Medicine 1990323 1246-1249.

13 Van Hagen PM, Krenning EP, Kwekkeboom DJ, Reubi JC, AnkerLugtenberg PJ, Lowenberg B et al. Somatostatin in the immune and haematopoietic system; a review. European Journal of Clinical Investigation $1994 \mathbf{2 4} 91-99$.

14 Ur E, Mather SJ, Bomanji J, Ellison D, Britton KE, Grossman AB, Wass JA \& Besser GM. Pituitary imaging using a labeled somatostatin analogue in acromegaly. Clinical Endocrinology $199236147-150$.

15 Colao A, Ferone D, Lastoria S, Marzullo P, Cerbone G, Di Sarno A et al. Prediction of efficacy of octreotide therapy in patients with acromegaly. Journal of Clinical Endocrinology and Metabolism 1996 $812356-2362$.

16 Borson-Chazot F, Houzard C, Ajzenberg C, Nocaudie C, Duet M, Mundler O et al. Somatostatin receptor in somatotroph and nonfunctioning pituitary adenomas: correlation with hormonal and visual responses to octreotide. Clinical Endocrinology $1997 \mathbf{4 7}$ 589-598.

17 Plöckinger U, Bäder M, Hopfenmüller H, Saeger W \& Quabbe H-J. Results of somatostatin receptor scintigraphy do not predict pituitary tumor volume- and hormone-response to octreotide therapy and do not correlate with tumor histology. European Journal of Endocrinology 1997136 369-374.

18 Colao A, Lastoria S, Ferone D, Varrella P, Marzullo P, Pivonello R et al. The pituitary uptake of ${ }^{111}$ In-DTPA-D-Phe ${ }^{1}$-Octreotide in the normal pituitary and in pituitary adenomas. Journal of Endocrinological Investigation 199922 176-183.

19 Postema PTE, Kwekkeboom DJ, van Hagen PM \& Krenning EP. Somatostatin-receptor scintigraphy in Graves's orbitopathy. European Journal of Nuclear Medicine 199623 615-617.

20 Postema PTE, Krenning EP, Wijngaarde R, Kooy PPM, Oei HY, ven den Bosch WA et al. $\left[{ }^{111}\right.$ In-DTPA-D-phe $\left.{ }^{1}\right]$-octreotide scintigraphy in thyroidal and orbital Graves' disease: a parameter for disease activity? Journal of Clinical Endocrinology and Metabolism $1994791845-1851$
21 Kahaly G, Diaz M, Hahn K, Beyer J \& Bockisch A. Indium-111pentetreotide scintigraphy in Graves' ophthalmopathy. Journal of Nuclear Medicine 199536 550-554.

22 Mansi L, Rambaldi PF, Bizzarro A, Panza N, Di Martino S, De Bellis A et al. Indium-111 octreotide in Graves' disease and in the evaluation of active exophthalmos. Quarterly Journal of Nuclear Medicine 199539 105-110.

23 Krassas GE, Dumas A, Pontikides N \& Kaltsas TH. Somatostatin receptor scintigraphy and octreotide treatment in patients with thyroid eye disease. Clinical Endocrinology $199542571-580$.

24 Durak I, Durak H, Ergin M, Yurekli Y \& Kaynak S. Somatostatin receptors in the orbits. Clinical Nuclear Medicine 199520237 242 .

25 Kahaly G, Görges R, Diaz M, Hommel G \& Bockisch A. Indium111-pentetreotide in Graves' disease. Journal of Nuclear Medicine $199839533-536$.

26 Gerding MN, van der Zant FM, Royen EA, Koorneef L, Krenning $\mathrm{EP}$, Wiersinga WM et al. Octreotide-scintigraphy is a diseaseactivity parameter in Graves' ophthalmopathy. Clinical Endocrinology $1999 \mathbf{5 0} 373-379$.

27 Krenning EP, Kwekkeboom DJ, Pauwels S, Kvols LK \& Reubi JC. Somatostatin receptor scintigraphy. Nuclear Medicine Annals 1995 $1-50$.

28 Colao A, Lastoria S, Ferone D, Pivonello R, Macchia PE, Vassallo Pet al. Orbital scintigraphy with $\left[{ }^{111}\right.$ In-Diethylenetriamice pentaacetic acid-D-Phe $\left.{ }^{1}\right]$-octreotide predicts the clinical response to corticosteroid therapy in patients with Graves' ophthalmopathy. Journal of Clinical Endocrinology and Metabolism 1998 83 3790-3794.

29 Bartalena L, Marcocci C, Bogazzi F, Bruno-Bossio G, Lepri A, Bagnolesi P \& Pinchera A. A new ophthalmopathy index for quantification of eye changes of Graves' disease. Acta Endocrinologica 1989121 190-192 (Suppl. 2).

30 Nocaudie M, Bailliez A, Itti E, Bauters C, Wemeau JL \& Marchandise X. Somatostatin receptor scintigraphy to predict the clinical evolution and therapeutic response of thyroidassociated ophthalmopathy. European Journal of Nuclear Medicine $199926511-517$.

31 Chang TC, Kao SCS \& Huang KM. Octreotide and Graves' ophthalmopathy and pretibial myxoedema. British Medical Journal 1992304158.

32 Kuyvenhoven JP, van der Pjil JW, Goslings BM \& Wiersinga WM. Graves' dermopathy: does octreotide scintigraphy predicts the response to octreotide treatment? Thyroid $1996 \mathbf{6} 385-389$.

33 Krassas GE, Dumas A, Pontikides N \& Kaltsas T. Somatostatin receptor scintigraphy and octreotide treatment in patients with thyroid eye disease. Clinical Endocrinology $1995 \mathbf{4 2} 571-580$.

34 Ozata M, Bolu E, Sengul A, Tasar M, Beyhan Z, Corakci A \& Gundogan A. Effects of octreotide treatment on Graves' ophthalmopathy and circulating sICAM-1 levels. Thyroid 19966 283-288.

35 Kung AWC, Michon J, Tai KS \& Chan FL. The effect of somatostatin versus corticosteroid in the treatment of Graves' ophthalmopathy. Thyroid $19966318-324$.

36 Uysal AR, Corapcioglu D, Tonyukuk VC, Gullu S, Sav H, Kamel N \& Erdogan G. Effect of octreotide treatment on Graves' ophthalmopathy. Endocrine Journal 199946 573-577.

37 Giusti M, Gussoni G, Cuttica CM, Giordano G \& the Italian Multicenter Slow-release Lanreotide Study Group. Effectiveness and tolerability of slow-release lanreotide treatment in active acromegaly: six-month report on an Italian multicenter study. Journal of Clinical Endocrinology and Metabolism 199681 20892097.

38 Caron P, Morange-Ramos I, Cogne M \& Jaquet P. Three-year follow-up of acromegalic patients treated with intramuscular slow-release lanreotide. Journal of Clinical Endocrinology and Metabolism 199782 18-22.

39 Colao A, Marzullo P, Ferone D, Marinò V, Pivonello R, Di Somma C et al. Effectiveness and tolerability of slow-release lanreotide treatment in active acromegaly. Journal of Endocrinological Investigation 199922 40-47.

40 Krassas GE, Kaltsas T, Dumas A, Pontikides N \& Tolis G. 
Lanreotide in the treatment of patients with thyroid eye disease. European Journal of Endocrinology 1997136 416-422.

41 Krassas GE, Dumas A, Kaltsas T, Halkias A \& Pontikides N. Somatostatin receptor scintigraphy before and after treatment with somatostatin analogues in patients with thyroid eye disease. Thyroid 19999 47-52.

42 Hansson HA, Petruson B \& Skottnerm A. Somatomedin-C in pathogenesis of malignant exophthalmos of endocrine origin. Lancet 1986 i $218-219$.

43 Krassas GE. Somatostatin analogues in the treatment of thyroid eye disease. Thyroid $1998 \mathbf{8} 443-445$.
44 Heufelder AE. Somatostatin analogues in Graves' ophthalmopathy. Journal of Endocrinological Investigation (Suppl to no. 7) 199720 50-52.

45 Wiersinga WM, Gerding MN, Prummel MF, Krenning EP \& Octreotide scintigraphy in thyroidal and orbital Graves' disease. Thyroid 19988 433-436.

Received 1 July 2000

Accepted 19 July 2000 